\title{
La formalidad del juego
}

\section{MIRTA HALPERT ZAGIEL}

$>$ Arquitecta, Doctora de la Escuela Técnica Superior de Arquitectura, Universidad de Sevilla

Universidad de Valparaíso

Facultad de Arquitectura

Márgenes

Espacio Arte Sociedad

La formalidad del juego

Julio 2013, Vol 10, № 12

pp. $52-59$

ISSNN 0718-4034

Recepción: Agosto 2012

Aceptación: Diciembre 2012

\section{RESUMEN}

Lectura e interpretación de un territorio mayoritariamente autogestionado. Producción de habitabilidad formal en suelos institucionalmente informales. Evolución del concepto de informalidad como acción no atenida a normas.

\section{PALABRAS CLAVES}

razón vital, ausencia de disponibilidad territorial, autogestión

The formality of the game

ABSTRACT

Understanding and interpreting of a mostly self managed territory. Creation of formal housing conditions on institutionally informal grounds. Concept of informality seen as actions not limited by the framework of standards. KEY WORDS

vital reason, absence of territorial availability, automanagement

\section{La formalité du jeu}

RÉSUMÉ

Lecture et interprétation d'un territoire principalement autogéré. Production d'habitabilité formel sur des sols institutionnellement informel. Evolution du concept d'informalité en tant qu'action qui ne répond pas aux normes. MOTS CLÉS

raison vitale, absence de disponibilité territorial, autogestion.

\section{LA CIUDAD}

Con bastante curiosidad e ingenuidad, propia de aquellos que esperan dejarse sorprender sin anteponer respuestas consideradas obvias, nos preguntamos hace unos años ¿dónde juegan los niños en estos cerros los juegos de la apropiación del espacio público, aquel que se entremete entre las viviendas y el tránsito vehicular buscando algo de planitud? ¿Dónde una rayuela, una pichanga ${ }^{1}$ que los vehículos esquivan (Figura 1), unas patinetas deslizándose entre los peatones?

Para quien se crió y educó en otras topografías, la impresión del impacto visual de la particular morfología de Valparaíso, así como de los recursos habitativos desarrollados, que sus residentes transformaron en el arte de poblar estos cerros, guardan hoy en día la misma frescura que podemos encontrar en las variadas descripciones e ilustraciones que sobre este territorio realizaron los primeros viajeros. Dibujos, croquis y grabados, así como pinturas, desde el siglo XVIII hasta bien avanzado la mitad del siglo XIX, de la mano de Mary Graham, Conrad Martens, Touchard, E. Dumont, Juan Mauricio Rugendas, entre otros. Además, junto a las fotografías de Castro y Ordoñez con que se comenzó a contar en la segunda mitad del siglo XIX, tomadas durante el viaje que realiza la Comisión Científica del Pacífico del año 1864.

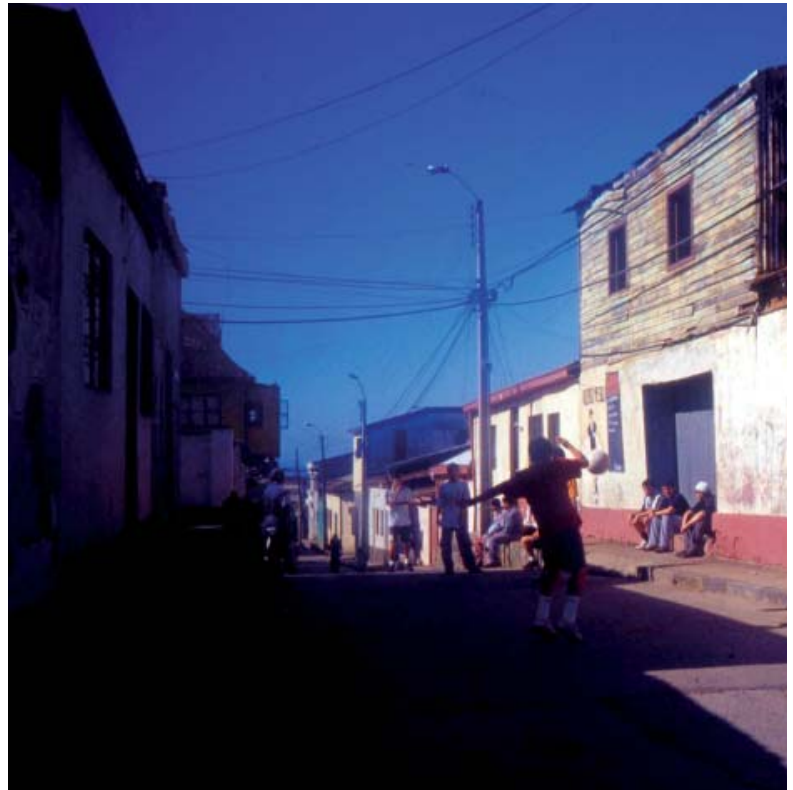

> Figura 1. Una pichanga en el Cerro Santo Domingo. Fotografía Lorena Estai 


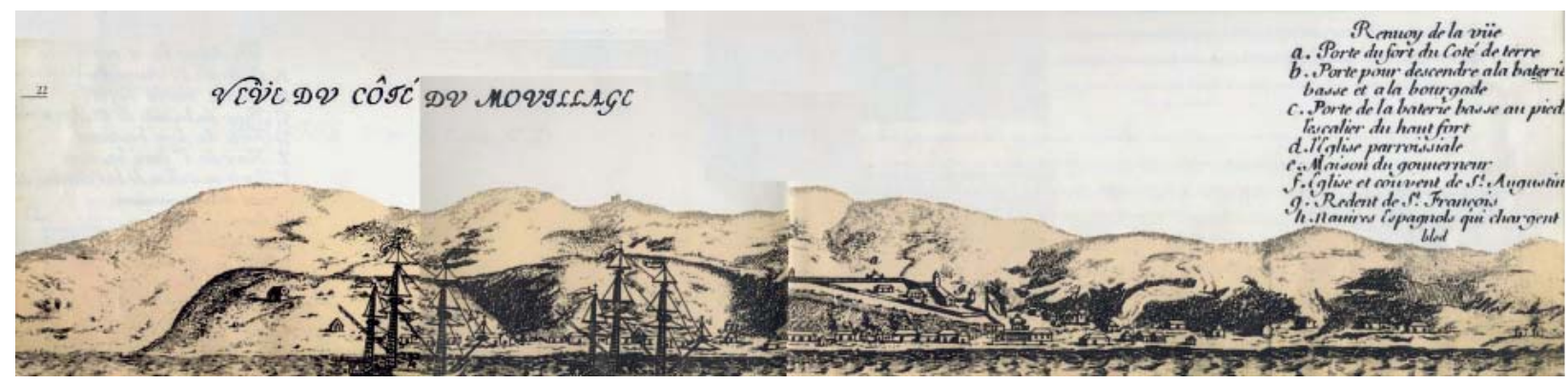

Figura 2. Valparaíso desde el Mar, Amadeo Frezier, Relación del viaje por el mar del Sur, 1712

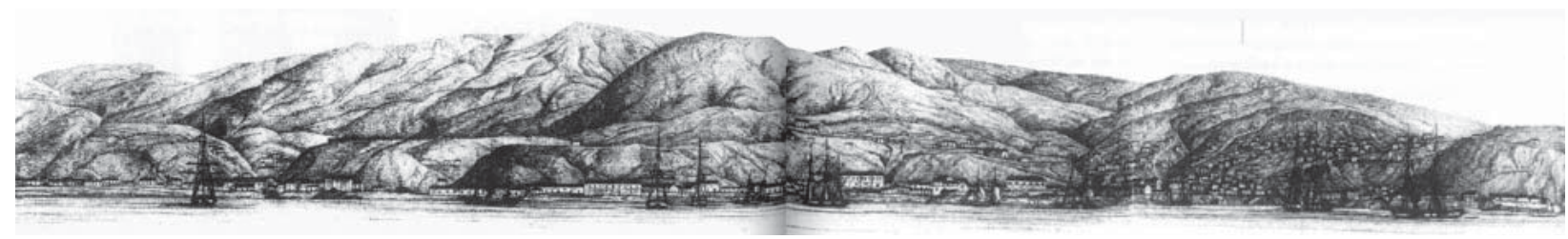

$>$ Figura 3. Panorama de la Ville de Valparaíso et ses environs. M. Blouet, 1834. République du Chili. Voyage de Mr. A. d’Orbigny

Una costa de abruptos y despojados cerros que Amadeo Frezier levantó en imágenes, cortes de terreno y descripciones en el año 1712, durante su viaje por el Mar del Sur² (Figura 2), y que M. Blouet representó en 1834 a bordo del Griffon ${ }^{3}$ (Figura 3). Dibujos de una ciudad extendida a lo largo de las primeras cotas del territorio, cuya vista desde el mar queda medianamente velada por los mástiles de los buques que frente a ella han atracado. Una incipiente ciudad portuaria conectada al comercio del mundo colonial del siglo XVIII y al libre comercio decimonónico de sus inicios independientes. Con escasos suelos cercanos al nivel del mar, la ciudad se fundó sobre la base del esfuerzo de trepar cerros.

En su escrito Visión de Valparaíso al finalizar la primera mitad del siglo $X I X$, Federico Walpole hace referencia a la presentación y descripción de la Bahía de Valparaíso que contenía la Guía General del Estado de Chile, la cual era repartida por los embajadores chilenos en las ciudades del mundo que recorrían alrededor del año 1840. Allí se señalaba el poco atractivo que tenían estas costas en la estación seca del año comparado con el verdor de otras latitudes en las costas del Mediterráneo o de Brasil (Calderón, 2001, p.200)4 . En él encontramos como contraparte de la aridez de la naturaleza que muestran las representaciones pictóricas, el empecinamiento de sus habitantes y del comercio de hacer vitales estas casi imposibles cuestas.

andando y andando sin parar, tenía lugar además una incesante llegada. Peter Handke

Una ciudad que compone sus propias categorías y metáforas, una ciudad cuyo solo nombre actúa tanto como metáfora de habitabilidad, como parece ser el contenedor de la comprensión de su historia particular.

Al revisar las diversas fuentes de estudio sobre los trazados territoriales de las conquistas, la ordenación del asiento de las insipientes instituciones y las habitabilidades originadoras de las configuraciones urbanas, encontramos que los gestos de los trazados territoriales impuestos durante finales del siglo XV y el XVI son el origen de la domesticidad de las ciudades coloniales latinoamericanas. Domesticidad que Roberto Fernández (1998, p. 18) ha denominado como la instalación de lo nulo, entendido en tanto ideología de la conquista que comprende el territorio como materialidad objetiva y no como espacio habitado y con paisaje transformado por sujetos ${ }^{5}$. De esta manera conforma el pliegue que transforma el proceso natural de autodefinición del desarrollo local y lo introduce en una abrupta vorágine de acontecimientos. Acontecimientos que desde mediados del siglo XIX comienzan a retomar con mayor fuerza su localismo en los debates sobre la identidad y el regionalismo. Así, el destino impuesto parece obligarnos a retomar siempre la historia desde las marcas territoriales que la conquista fijó.

Si podemos decir que los hechos de las conquistas y los actos de las fundaciones son los gestos que inauguran las ideas de las ciudades del orden, a lo largo de la historia urbana en todas las culturas, resulta especialmente relevante en la historia de las ciudades de Latinoamérica, Valparaíso. Valparaíso, ciudad infundada, vista en un inicio tan sólo como la bodega de Santiago, ciudad capital, crea en su hacer el orden de lo posible. El orden de lo práctico, el orden del deseo, el orden de la frontalidad al mar. Y vivifica estos valores ordenadores de autodefinirse entre su particular topografía y la razón vital de su existencia. Un paisaje natural construido como paisaje cultural por una arquitectura que vivifica la idea de ella misma en tanto estatuto de caligrafía cultural ligada a la existencia como señala José Ramón Moreno (2005, p.10) ${ }^{6}$. Al no haberse fundado, en ella no aplica ningún esquema ideal, por lo que podemos decir que se concreta con el uso (Cacciari, 2002) ${ }^{7}$. Probablemente se pueda decir también que se concreta en la idea de que las teorías de los orígenes no son sino maneras de definir cada vez mejor lo que siguió (Berger, 1980, p. 17) ${ }^{8}$, en tanto impulsos ordenadores que a la vez respaldan y justifican actuares institucionales posteriores.

En esta ciudad latinoamericana, los mitos habitativos se pueden remontar a las acciones constructivas de aquellos que llegaron a un territorio sin prácticas de ocupación significativas y sobre el cual idearon sus espacios. Acciones sobre las cuales podemos hoy en día decir que la experiencia del territorio se constituye y manifiesta en habitación cuando se constatan las características específicas sobre las que se hace el cobijo. Cuando se habita el plan sobre los rellenos que se hicieron de los escombros que dejaron los terremotos y sobre los restos de los cascos de los barcos encallados que contuvieron arenas y cerros recortados, cuando se habita el mar sobre el que el territorio se extendió y al que se le construyen mi- 
radas, cuando se habitan las laderas de los cerros a lo largo de las cotas, cuando se habita el aire al que se le construyen suelos.

\section{EL RECICLAJE}

Ciudad de las circunstancias y la contingencia, en la cultura de Valparaíso yace el reciclaje como necesidad y oportunidad, encontramos que en 1850 se inició un activo proceso de excavación de las laderas de los cerros, especialmente en el sector de la Aduana, la Plaza Municipal (actual Plaza Echaurren) y la calle de la Planchada (actual calle Serrano) para ganar terreno al mar, precisamente con los materiales excavados en los cerros (Ortega, 1987, p. 109) ${ }^{9}$. Estos movimientos de tierras resultaron suficientemente significativos como para que en 1856, cuando Harry Edmund Edgell realizara la ilustración de la ciudad nombrada View of Valparaíso, retratara en el extremo de la Bahía al Cerro Artillería con su corte vertical de color rojizo resultado de esas excavaciones, señalada así como una herida de la topografía natural.

Terremotos y maremotos, incendios y temporales destruyen su arquitectura, pero dejan materia prima para ganarle suelo al mar y para transformar en la medida de lo posible las laderas de sus cerros. Es el contrapunto del ingenio que recicla todo material perdido.

Un puerto que florece en el cruce comercial de las mercaderías que el país produce y exporta, y de las mercaderías que el país requiere e importa, junto al tránsito de productos desde y hacia otros países, es lo que encontramos detallado en la exhaustiva descripción que hace Bladh en 1881 de estos cientos de mercancías. Productos que se transforman en las múltiples alternativas de su reciclaje tras los temporales, por lo que nos permitimos presentar esta extensa cita (en Calderón, 2001, p. 87):10

Este puerto es el primero que visitan los barcos que llegan del Cabo de Hornos (los puertos situados en el sur de Chile son demasiado poco visitados para hacer excepción), y es el último en que fondean los que vienen del norte destinados al sur. De los puertos norteños se trae: cacao, sombreros de paja, "Pastillas" (una especie de rapé), cigarros habanos, peleterías, tejidos de lana, pisco, maíz, índigo, abarrotes y drogas, sal y salitre, plata y oro. Del centro y del norte del Brasil: café y azúcar. De los Estados Unidos: muebles, "tocuyo" (género no blanqueado de algodón grueso), harina, jamones, carne salada y tocino, planchas de cobre, jabón, pez, alquitrán, velas de esperma, galletas de marinero, ginebra y ron, arroz, sidra, tabaco, cigarros, etc. De Inglaterra: vinos, aguardientes y ginebra, lienzo y telas de algodón, lanillas, alfombras preciosas, medias de seda, sombreros, drogas, papel, vidrio, loza, hierro y acero, además de diversas mercaderías fabricadas de este metal, como armas, clavos, clavitos de herraduras, herramientas de labranza y de carpintería, etc., pólvora, instrumentos, carne salada, tocino, pescado y mantequilla, tela de buque, cables, materias tintorantes, pez y alquitrán, etc. De España: acero de Mondragón, hierro de Vizcaya, sedas, aceite de oliva, vinos de Cataluña, Jerez y Málaga, aguardiente y papel, etc. De Francia, Holanda y los puertos alemanes: lanilla, sedas, espejos, vidrio, loza, ropa confeccionada y calzado, trabajos de joyería, algunos verdaderos y muchos falsos, géneros delgados, lienzos, paños de mesa, géneros de colcha, pinturas, licores, vinos, cognac, ginebra, aceite de oliva, encajes, bordados, trabajos en bronce, relojes, armas de fuego, pólvora, muebles, navajas de afeitar, perfumes, conservas, etc. De Italia: fideos, higos, aceite de oliva, conservas, azufre, cera, miel, drogas, etc. Del norte de Chile: lingotes de cobre, barras de plata, cueros, carne seca ("charqui"), y fruta seca. Del sur de Chile: trigo, troncos, arbotantes, tablas, vino, aguardiente, caballos, asnos, mulas, "charqui", cueros, sebo, jabón y choros (una especie de conchas grandes que se comen). Del Archipiélago de la Sociedad: Perlas y madreperla. De las islas de Chiloé: jamones, "charqui", sebo y jabón. De Buenos Aires, Paraguay y Río Grande: yerba mate y tabaco. El lujo y la opulencia general permiten vender en el mismo país la mayoría de estos artículos, con excepción de aquellos que el mismo país produce; como ser: oro, plata, cobre, plomo, trigo, cebada, drogas sudamericanas, "charqui", sebo, jabón sudamericano, cueros de buey, vaca y caballo, cueros de animales salvajes, frutas secas, avellanas y nueces, especias, entre las cuales gran cantidad de pimienta de Cayena, vino del país y aguardiente, etc., los que, después de las necesidades del país, constituyen artículos de exportación bastante considerables.

Maremotos que destruyen navíos llenos de carga, temporales que empapan lo que espera ser embarcado a otro puerto o trasladado a otra región y que no llegó a cobijo en las bodegas. Restos que el mar abandona o devuelve y que en el proceso de su reciclaje consolida el camino que va de proyectar con la medida de lo posible a imaginar con la medida de lo deseable.

\section{EL HABITAR}

así como no funciona la oposición abrupta

entre lo tradicional y lo moderno,

tampoco lo culto, lo popular y lo masivo

están donde nos habituamos a encontrarlos

Néstor García Canclini (1990, p. 14) $)^{11}$

La arquitectura de habitar el afuera, como lo nombra Sergio Rojas en El desastre del lugar (2001, p. 139) ${ }^{12}$, y sobre lo cual dice:

no se trata de que habiendo estado los hombres en la intemperie, han construido ahora -después- la casa, como para ya no estar simplemente en la intemperie, sino que precisamente construyendo la casa es como el hombre habita la intemperie. Habita el hombre en medio de la tempestad. El afuera no queda abolido, pues es en el afuera en donde se construye la casa.

Y con ello, el dar forma al territorio en esta ciudad, nos coloca delante de la reflexión sobre la convivencia de lo formal y lo informal, donde la idea de la composición heterogénea resulta pertinente para nombrar la superposición resultante de arquitectura, trazado y territorio.

Cabría aquí hacer un breve paréntesis para referenciar la cita de García Canclini de 1990 que explicita la idea de lo híbrido como proceso de dislocación de los contenidos conceptuales en campos estáticos, y así entenderla dentro de lo que plantea dos décadas después en el marco de la metáfora y el concepto viajero. En el 2010 García Canclini dice sobre el concepto de hibridación: salió de la biología del siglo XIX, se encontró con la crítica literaria de Mijail Bajtín, fue reasumido por la crítica poscolonial en la India y por el pensamiento posfundamentalista en América Latina. Y agrega citando a Mieke Bal: dado que al viajar los conceptos se vuelven flexibles, sus migraciones pueden ser "una ventaja más que un peligro” (García Canclini, 2010, p.124) ${ }^{13}$. Así la hibridación sería la resultante válida del concepto interpretador del entramado resultante de lo formal y lo informal. 
No sólo la migración de los conceptos puede ser una ventaja más que un peligro sino también la transformación temporal de los mismos, en tanto sean pensados en vistas de su utilidad:

si cabe sustituir unos conceptos por otros, es bajo la condición de problemas nuevos, y de un plano de inmanencia distinto con respecto a los cuales (por ejemplo) "Yo" pierda todo sentido, el inicio pierde toda necesidad, los presupuestos toda diferencia - 0 adquieren otras-.

Relaciones que desarrollan Deleuze y Guattari en ¿Qué es la filosofía? (1991, p. 33) ${ }^{14}$, y permite entender y nombrar procesos de cambio en las interpretaciones sobre la ciudad. Especialmente en las ciudades entendidas como estructuras cambiantes pero no necesariamente mutantes a largo plazo. En particular las latinoamericanas, donde se pueda decir de ellas que al estar constantemente en procesos de crecimiento y expansión se desdibujan de una cierta idea de ciudad inicial, que no sólo las fundó sino que se consolidó en las primeras décadas de los países independizados. Idea que se considera mayormente reflejada por las áreas patrimoniales, pero que en Valparaíso está fuertemente interpretada más que en las construcciones patrimoniales, en su historia de asentamientos en el plan y en los cerros. Así, el concepto idea de ciudad como estructura de orden simbólico reconocible por sus habitantes, que plantea Joseph Rykwert en 1976, en tanto idea formal cuyo origen puede ser una leyenda o un decreto institucional, puede también ser, como dice Rafael Moneo sobre el estudio de Rykwert, el sue ño que de ella se construyó (1976, p. x ${ }^{15}$, y que en Valparaíso se cambia por otro sueño, el de la necesidad expresada en órdenes territoriales de la experiencia.

Hacer la ciudad desde el viento y pensarla desde el viento. Hacer la ciudad desde los reflejos especulares del sol sobre el mar y pensarla desde esos reflejos. Los cerros de Valparaíso están pregnados por un modo de hacer la habitabilidad mediante instalaciones que domestican el territorio habitado, casi sin transformarlo (Figuras 4 y 5). La generación de estas construcciones, entendidas desde los mitos habitativos que acompañan a la ciudad, leídas, interpretadas y entendidas como construcciones fundantes de identidades e imaginarios, así como los ensayos que sobre sus posibilidades de habitabilidad se han construido, pueden ser estudiados desde varias disciplinas.

Desde las experiencias fenomenológicas descritas por Gaston Bachelard en La poética del espacio es que Giulio Carlo Argan propone extender a la ciudad el estudio que hizo Bachelard sobre la casa. Así, nos dice, surgiría inmediatamente la infinita variedad de valores simbólicos que pueden asumir los datos visivos del contexto urbano en el individuo, de los significados que asume, para cada uno de sus habitantes, la ciudad (1984, p. 221) ${ }^{16}$.

Desde las experiencias urbanas estudiadas por los arquitectos, entre muchas otras y significativa para la cultura chilena, encontramos las que Ana María Barrenechea dirigió en el proyecto Santiago visto por sus habitantes, encuestas a los residentes. Es un proyecto de investigación sobre las experiencias de los santiaguinos realizada en el año 1966, sobre las propuestas de Kevin Lynch en La imagen de la ciudad (Barrenechea, 1966, p, 20) ${ }^{17}$.

Desde las diversas experiencias estudiadas por sociólogos, antropólogos, literatos, etc., se puede ver el proyecto Culturas urbanas desde sus imaginarios sociales, en América Latina y España impulsado y dirigido por Armando Silva a través del Convenio Andrés Bello. Armando Silva

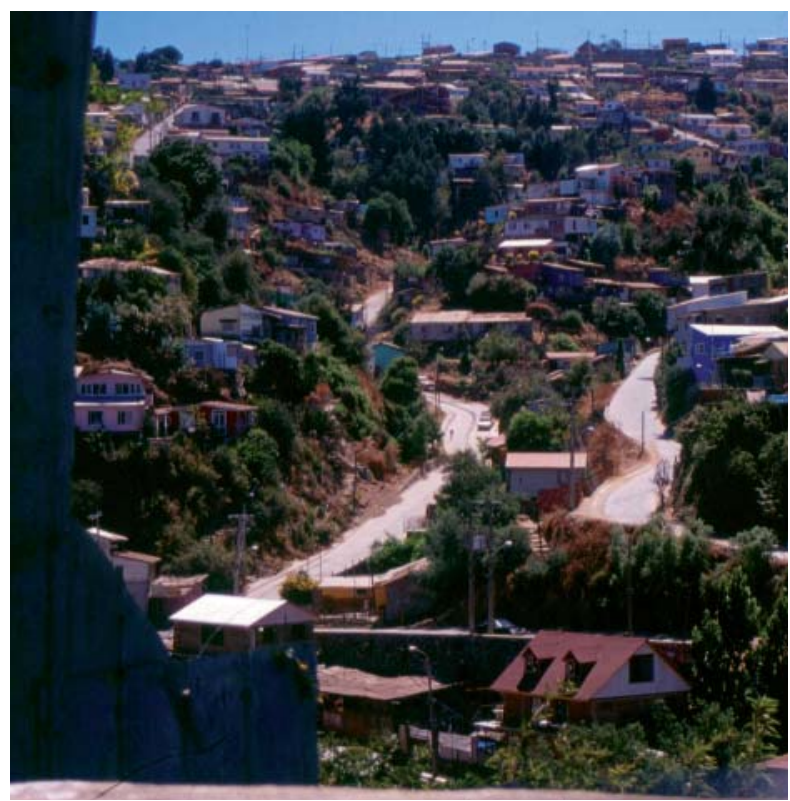

$>$ Figura 4. Habitabilidad auto-generada. Fotografía Mirta Halpert

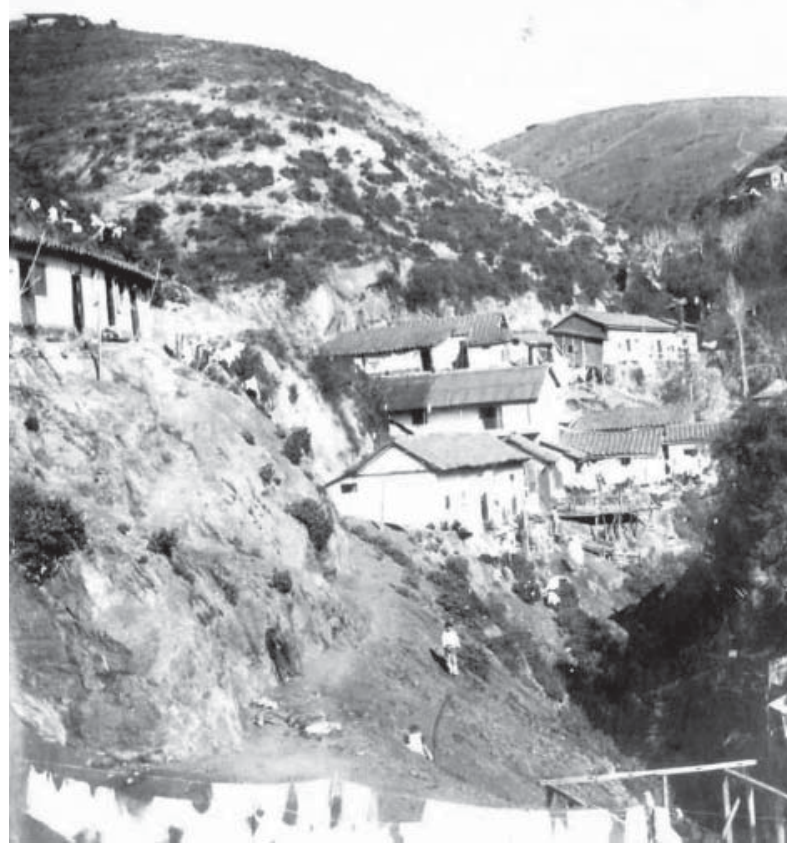

$>$ Figura 5. Quebrada San Francisco, fotografía Castro y Ordoñez, 1863-64. Fuente Sagredo, Rafael, y Puig-Samper, Miguel Ángel, (Editores), Imágenes de la Comisión Científica del Pacífico en Chile 


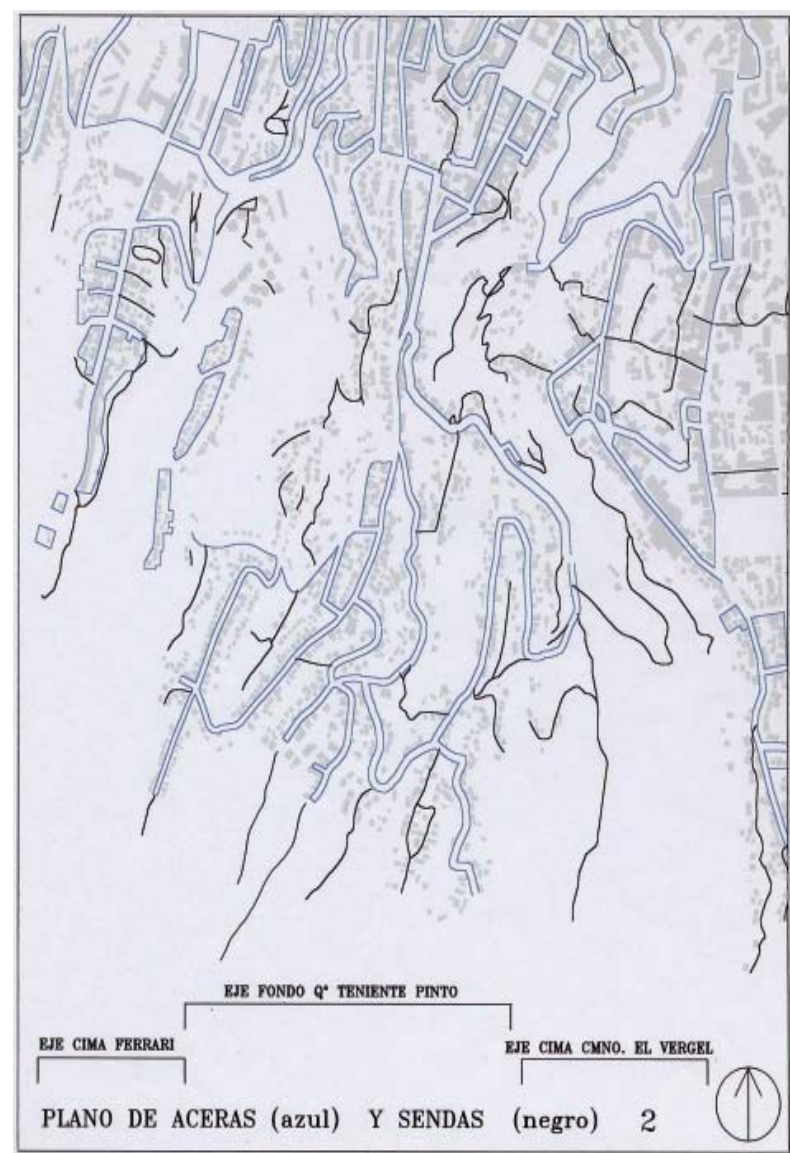

> Figura 6. Plano de aceras y sendas. DIPUV 35-2000

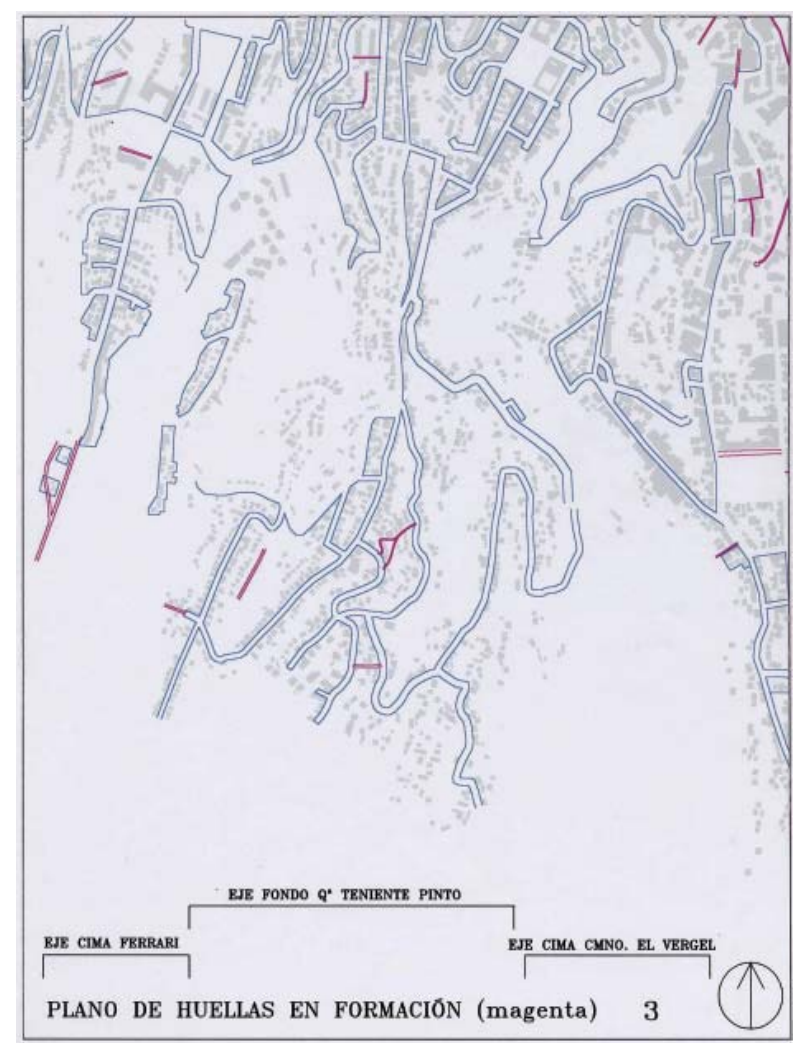

> Figura 7. Plano de huellas en formación. DIPUV 35-2000 propone conocer maneras de ser urbanos y, a la vez, concebir modos comparativos entre ciudadanos de distintas ciudades. Así, dice en Imaginarios urbanos, metodología la finalidad del proyecto se dirige a captar esa ciudad subjetiva que llevan en sus mentes y en sus modos de vida los ciudadanos. No vamos tras la ciudad física, sino hacia aquella hecha por la percepción ciudadana (2004, p.14) ${ }^{18}$.

Desde la experiencia y el quehacer arquitectónico buscamos la geografía "habitada y poblada de signos" (Pardo, 1991, p. 61$63)^{19}$ de esta ciudad a través de diversos estudios, entre ellos la investigación sobre las apropiaciones que el ejercicio formal -por repetitivo, reglado y consecuente- del juego informal y callejero de los niños hace del espacio público. José Luis Pardo nos dice que geografía "también quiere decir inscripción en la tierra”, es decir:

desde el momento en que se deposita en la tierra un signo (cualquier fragmento de naturaleza capaz de "hacer" territorio), una letra, ya se ha doblado el espacio "natural" con un espacio segundo, artificial ("poético").

Encontramos que en cada compleja y sostenida relación entre los signos habitativos y el territorio demarcado, que identificamos en las sendas y huellas en formación estudiadas entre el Cerro Yungay y el Cerro La Cruz ${ }^{20}$, es que viene a hacerse manifiesta la arquitectura del habitar (Rojas, 2002) ${ }^{21}$ (Figuras 6 a 8) como extensión del cuerpo. Y por ello, podemos decir que encontramos una relación que siempre implica la palabra aquí, como antecesora del vínculo que sostiene al lugar, y hace de él un "enunciado" (Hirschfeld, 2000 , p. 8) ${ }^{22}$. Cada signo que reconocimos como lugar se presentaba como un enunciado del modo de construir su propio habitar.

Para ello nos propusimos seguir las indicaciones de Beatriz Sarlo y mirar en detalle en una relación de cercanía pero no de complicidad (1997, p. 8) ${ }^{23}$. Esto nos permitió, tras largos ires y venires, encontrar un tono de voz que habla de la particularidad local en la descripción de sus características apropiaciones de los lugares exteriores. Así mismo recogimos la propuesta de Sarlo en el modo de observar lo familiar, lo que se repite y por ello significa, lo que se ve poco y, también por eso, tiene sentido. Una observación recurrente, que vuelve sobre el objeto en el intento de evitar cargar desde la mirada arquitectónica, sentidos costumbristas y antropológicos, para develar hechos de la construcción territorial de la habitación. Ejercicio de subir y bajar cerros por escaleras que sólo sus residentes encuentran, cruzar quebradas y en un giro del cuerpo perder la lejanía marítima para encontrar extensos sectores habitados que se miran entre las laderas enfrentadas. Ejercicio que realizamos con el equipo de estudiantes del proyecto de investigación DIPUV 35-2000 compuesto por María José Bardi, Lorena Estai, Diego González, Pietro Papic y Mauricio Torres.

Todo territorio que excedió las pendientes y las distancias que las normativas de construcción oficiales fijan, se consolidó en un particular e informal proceso de autogestión habitacional. Lo que se tramó entre el territorio proyectado y el territorio adaptado son límites desdibujados en una gráfica, que habla de la permeabilidad del uso y de la continuidad urbana.

Distante de la postal sobre la muy fotografiada composición plástica que la frágil situación económica de la ciudad en las últimas décadas ha dejado registrada en las huellas del deterioro, y la habilidad artesanal de sus residentes para re-componer lo que el tiempo desgastó especialmente en las zonas residenciales, es que se encuentra el enunciado de habitabilidad. Registros fotográficos 
que han llevado a que en cierta medida se entienda a la ciudad como que en cierto modo ya es una postal, la ciudad existe en el imaginario colectivo como un álbum virtual de fotografías de los lugares obligados dice Sergio Rojas (2005, p. 5) ${ }^{24}$. El enunciado de habitabilidad se encuentra, de manera muy particular en el reverso de la postal que hay que buscar.

La habitabilidad de la ciudad, aquello que constituye su modo particular de crear otros mitos, sólo se lo puede encontrar en lo que en tanto reverso de la postal nombramos como reconocimiento de aquellos espacios que no se señalan, y que en una primera mirada se registran más como adaptabilidad de tipologías que como conformación de nuevos recodos de posibilidades públicas. Allí encontramos que una extensión del pasillo deriva en un lugar de reunión, una baranda al borde de la acera genera tanto un espacio de contención para detenerse así como cumple con su rol protector. Y la formalidad del juego callejero de pasajes y baldíos se revierte en la consolidación de un retazo del espacio público, renombrado como la cancha.

En el mismo espíritu de que cada cerro es un barrio, cada cerro es un club de football local, si bien en pocos cerros tienen canchas cercanas a las reglamentarias con graderías y lugares de vestuarios, en casi todas hay espacios para 2 arcos (Figuras 9 al 11). El juego es formal, exige sus delimitaciones de espacios y sea como sea la disponibilidad de los lugares identificados en cada juego, siempre encuentran localización arcos, media cancha, área grande y área chica.

La aleatoriedad que a primera vista se percibe en la construcción popular de los espacios públicos y de las viviendas en los cerros, no puede ser leída según un principio de caos, podemos decir que las condicionantes de las posibilidades se encuentran predeterminadas entre lo particular del suelo disponible y la mirada al sol. Donde el deseo de habitar construye la medida de las posibilidades y la apropiación construye con los imaginarios. Frente a la medida de lo necesario, la medida de lo posible. Las direcciones que adoptan las múltiples escaleras de accesos y el ángulo de la mirada en la ubicación de la planta inicial, respecto al sitio de apropiación, se constituye en un elemento de poder interno.

Los conceptos no son eternos, pero ¿se vuelven acaso temporales por ello?

\section{Si un concepto es mejor que uno anterior}

es porque permite escuchar variaciones nuevas

y resonancias desconocidas,

porque efectúa reparticiones insólitas,

porque aporta un Acontecimiento

que nos sobrevuela

Deleuze y Guattari (1999, p. 33)

La existencia de una tradición de casi 200 años de asentamientos informales en los cerros, nos obliga a nombrar a esta informalidad formalizada - dejando de lado clasificaciones o identificacionescomo una estructura perdurable y persistente.

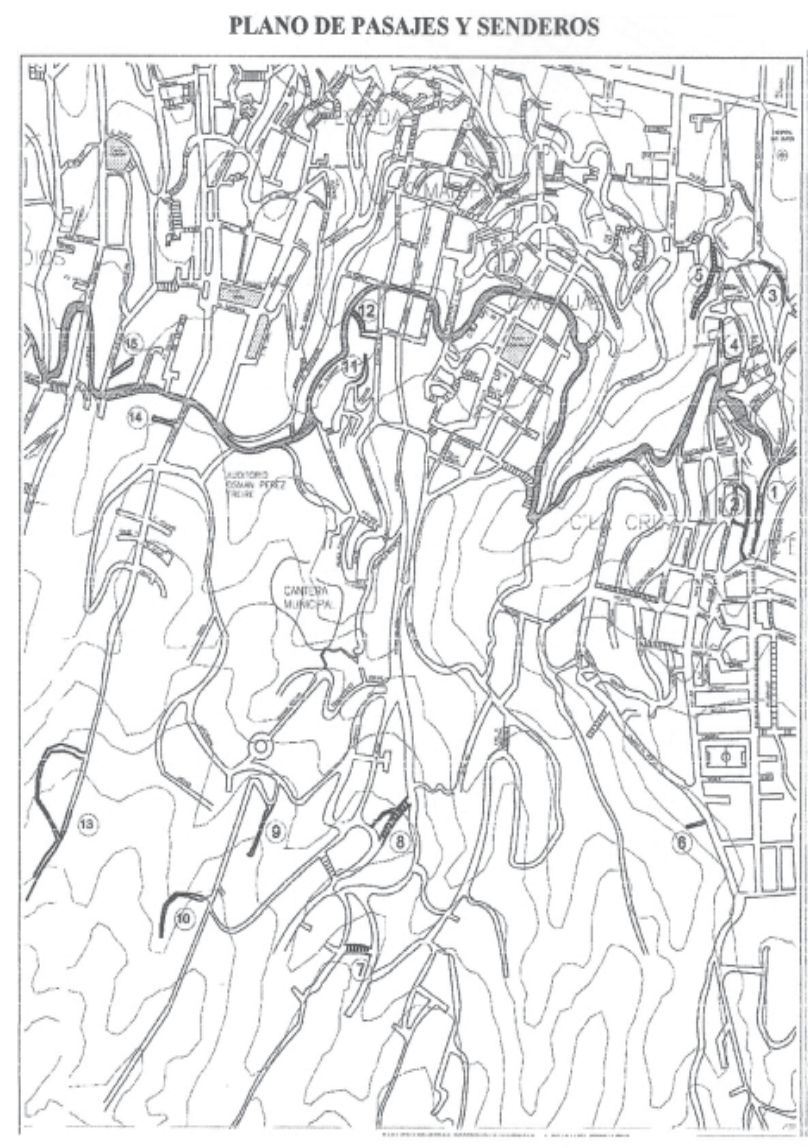

1. Pje. Villagra, cerro La Cruz.

2. Pje. Paul Sen, cerro La Cruz

3. Pje. Júpiter, cerro La Cruz

4. Pje. F. Varela, cerro La Cruz

5. Pje. Mauten, escalera Almendro, cerro $\mathrm{LaCruz}$

6. Pje. Particular, cerro La Cruz

7. Pje. Ancud, escalera Colo-Colo,

cerro Mariposa

8. Pje. Real, cerro Mariposa

9. Pje. Las Rosas, cerro Mariposa

10. Pje. 2, sector $\mathrm{H}$, cerro Mariposa

11. Pje. Principal, villa Adolfo Ibañez

cerro Mariposa

12. Pje. Mayorga, cerro Mariposa

13. Calle de tierra, Ferrari Alto,

cerro Florida

14. Pje. M. Mena, cerro Florida

15. Pje. Yerbas Buenas, cerro Bellavista

$>$ Figura 8. Plano de pasajes y senderos. DIPUV 35-2000

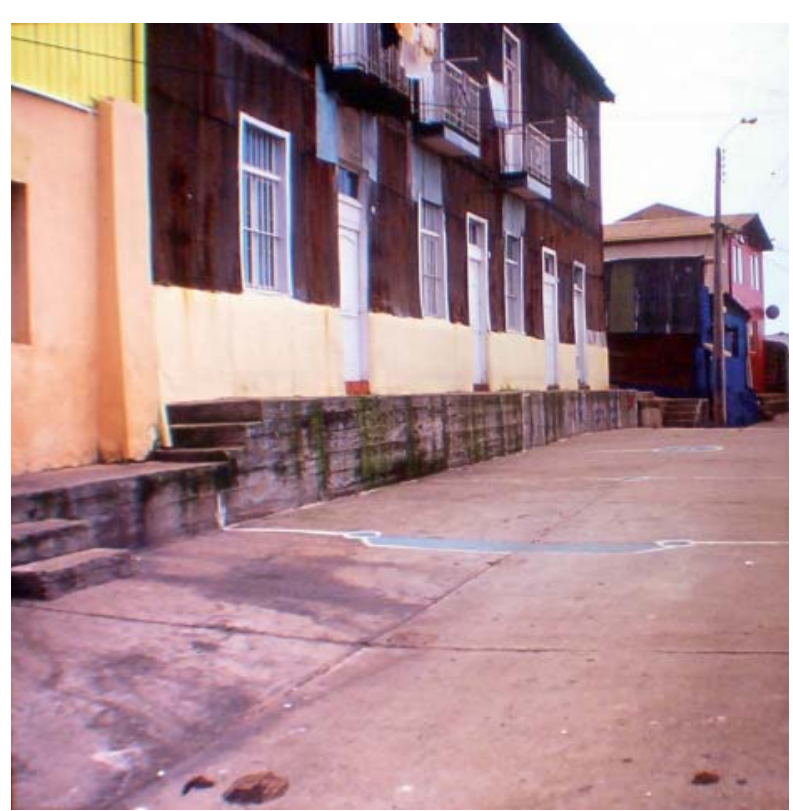

> Figura 9. Territorio enunciado, Pasaje José Ortega. Fotografía Diego González 


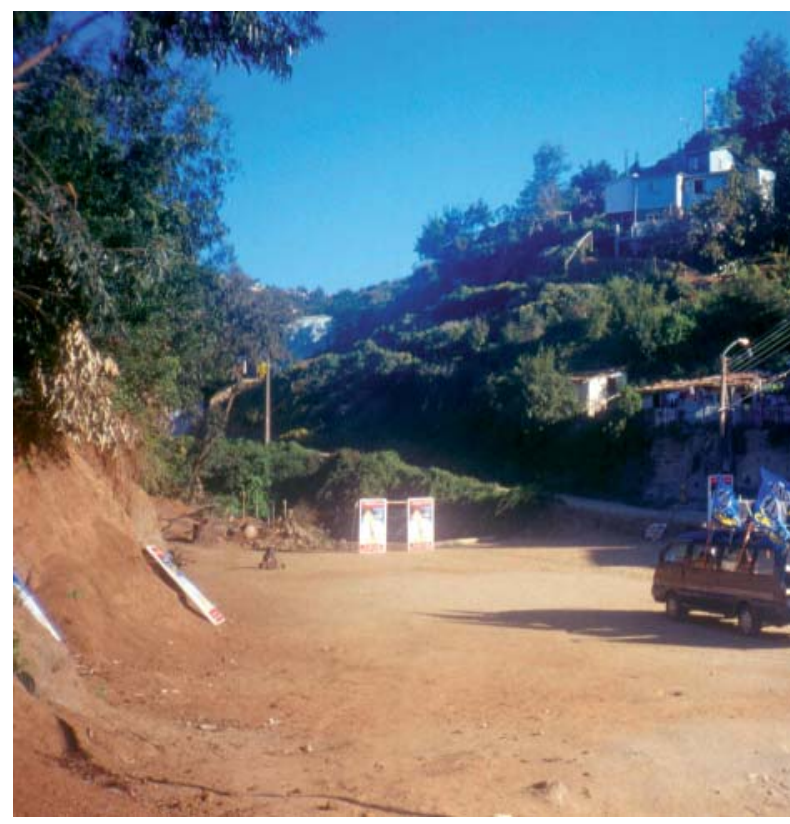

Figura 10. Disponibilidad para el juego, Cerro La Cruz. Fotografía Mauricio Torres

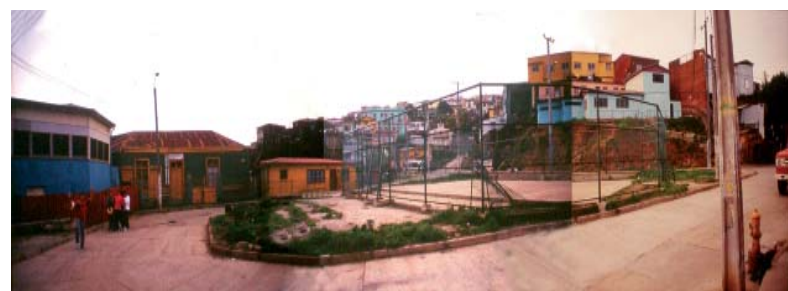

> Figura 11. La formalidad del juego, Cerro Perdices. Fotografía Mirta Halpert

\section{NOTAS}

1 Pichanga: término local para el libre ejercicio del football en cualquier tipo de espacio dimensional y material, simbólicamente demarcado por diversos elementos que indican el ansiado arco del equipo contrario.

2 Valparaíso desde el Mar, Amadeo Frezier, en Subercaseaux, Benjamín, (1940), Chile o una loca geografía, 2001.

3 Panorama de la Ville de Valparaíso et ses environs. République du Chili. Voyage de Mr. A. d'Orbigny. Fuente Encina, Francisco, y Castedo, Leopoldo, Historia de Chile, tomo II.

4 Extracto en Alfonso Calderón y Marilis Schlotfeldt. Texto completo publicado en Boletín de la Academia Chilena de la Historia $N^{\circ} 6$, año III, $2^{\circ}$ semestre 1935.

5 Fernández, Roberto, (1998), El Laboratorio Americano, Arquitectura, Geocultura y Regionalismo.

6 Moreno Pérez, José Ramón, (2005), Sobre la incierta (por oculta) relación entre arquitectura y escritura, inédito.

7 Cacciari, Massimo, (2002), “Nómadas prisioneros”, Casabella 705. 8 Berger, John, (1980), Mirar, 1998.

9 En: Ortega, Luis, (1987) "Valparaíso: comercio exterior y crecimiento urbano entre 1800-1880", en: Valparaíso 1536-1986.

10 Carlos Eduardo Bladh, viajero sueco, hace la descripción de las mercaderías que circulaban en la década del ' 20 del siglo XIX por el puerto de Valparaíso: En: “Valparaíso entre 1821 y 1828”, en Calderón y Schlotfeldt. El texto completo Republiken Chile Arent 1821-1828, Estocolmo 1837, se encuentra traducido por la Revista Chilena de Historia y Geografía, № 15, La República de Chile 18211828, Santiago, 1951.

11 Culturas híbridas. Estrategias para entrar y salir de la modernidad, (1990).

12 “El desastre del lugar”, (2001), en M. Halpert Ed. Otras miradas, otras preguntas.

13 García Canclini, Néstor, (2010) La sociedad sin relato.

14 Deleuze, Gilles y Guattari, Félix, (1991), ¿Qué es la filosofía?

15 Rykwert, Joseph, (1976), La Idea de Ciudad, Antropología de la forma urbana en el mundo antiguo.

16 En Historia del arte como historia de la ciudad, 1984.

17 Sobre las propuestas de Kevin Lynch, Ana María Barrenechea dirigió el proyecto de investigación basado sobre encuestas a los residentes: "Santiago visto por sus habitantes", referenciado en revista auca № 2, Santiago, 1966.

18 En Imaginarios urbanos, metodología, p.14. Convenio Andrés Bello, Bogotá, 2004. Los proyectos publicados hasta el 2005 fueron llevados a cabo por: Armando Silva en Bogotá; Milagros Aguirre, Fernando Carrión y Eduardo Kingman, en Quito; Luciano Álvarez y Christa Huber en Montevideo; Ferran Escoda en BarceIona; y, Carlos Ossa y Nelly Richard en Santiago de Chile. En el 2006 se han publicado los proyectos sobre: Sao Pablo por Lisbeth Rebollo; Caracas por Víctor Bravo. En el 2007: La Paz por Carlos Villagómez; También han participado: Asunción, Buenos Aires, Lima, Panamá, México. 
19 Pardo, José Luis, (1991), Sobre los espacios, pintar, escribir, pensar, Ediciones del Serbal, Barcelona.

20 Estudio realizado entre los ejes de cima Av. Ferrari y Camino El Vergel, entre la cota 100 y la 300 aproximadamente.

21 Rojas, Sergio, (2002), “El sofisticado habitar humano”, Catálogo de Pablo Rivera para la 25a Bienal de San Pablo, Dirección de Asuntos Culturales del Ministerio de Relaciones Exteriores de Chile.

22 Hirschfeld, Ariel, (2000), Reshimot al Makom (Local Notes), Am Oved Publishers Ltd, Tel Aviv.

23 En: Instantáneas, Medios, ciudad y costumbres en el fin de siglo, 1996, Espasa Calpe Argentina / Ariel, Buenos Aires, $2^{a}$ ed., 1997.

24 En: "Valparaíso Revisitado / Deshabitar La “Postal”", en Rodrigo Casanova, (2005), Valparaíso Revisitado.

\section{BIBLIOGRAFÍA}

ARGAN, Giulio Carlo, (1983) Historia del Arte como Historia de la Ciudad, Editorial Laia, Barcelona, 1984.

BARRENECHEA, Ana María, (1996) "Santiago visto por sus habitantes", auca № 2, Santiago.

BERGER, John, Mirar, (1980), Ediciones de la Flor, Buenos Aires, 1998.

BLADH, Carlos Eduardo, (1838) “Valparaíso entre 1821 y 1828”, en Calderón y Schlotfeldt, p. 372. El texto completo Republiken Chile Arent 18211828 , Estocolmo, se encuentra traducido por la Revista Chilena de Historia y Geografía, № 15, La República de Chile 1821-1828, Santiago, 1951.

CACCIARI, Massimo, (2002) “Nómadas prisioneros”, Casabella 705. Traducido en: Moreno Pérez, José Ramón, “Textos de Teoría y Composición Arquitectónica”, Sevilla - Málaga, 2002-2011.

CALDERÓN, Alfonso y SCHLOTFELDT, Marilis, (2001) Memorial de Valparaíso, RIL editores, Santiago de Chile.

DELEUZE, Gilles y GUATTARI, Félix, (1991) ¿Qué es la filosofía?, Editorial Anagrama, Barcelona, 5ª edición, 1999

ENCINA, Francisco, y CASTEDO, Leopoldo, (1966) Historia de Chile, tomo II, Empresa Editora Zig-Zag, 6a edición, Santiago.

FERNÁNDEZ, Roberto, (1998) El Laboratorio Americano, Arquitectura, Geocultura y Regionalismo, Editorial Biblioteca Nueva, Madrid.

GARCÍA CANCLINI, Néstor, (1990) Culturas híbridas. Estrategias para entrar y salir de la modernidad, Editorial Grijalbo, México.

, (2010) La sociedad sin relato, Katz Editorial, Buenos Aires - Madrid.

HIRSCHFELD, Ariel, (2000) Reshimot al Makom (Local Notes), Am Oved Publishers Ltd, Tel Aviv.

MORENO PÉREZ, José Ramón, (2005) Sobre la incierta (por oculta) relación entre arquitectura y escritura, inédito, ETSA Sevilla.

ORTEGA, Luis, (1987) "Valparaíso: comercio exterior y crecimiento urbano entre 1800-1880", en: Valparaíso 1536-1986, Instituto de Historia, Universidad Católica de Valparaíso, serie Monografías Históricas / 1, Ediciones Altazor.

PARDO, José Luis, (1991) Sobre los espacios, pintar, escribir, pensar, Ediciones del Serbal, Barcelona.

ROJAS, Sergio, (2001) “El desastre del lugar”, en M. Halpert Ed. Otras miradas, otras preguntas. Ediciones Universidad Central, Santiago de Chile.
(2002) "El sofisticado habitar humano", Catálogo de Pablo Rivera para la 25a Bienal de Sao Pablo, Dirección de Asuntos Culturales del Ministerio de Relaciones Exteriores de Chile.

(2005) “Valparaíso Revisitado / Deshabitar La “Postal”", en Rodrigo Casanova, Valparaíso Revisitado, LOM Ediciones, Santiago.

RYKWERT, Joseph, (1976) La Idea de Ciudad, Antropología de la forma urbana en el mundo antiguo, Editorial Hermann Blume, Madrid, 1985.

SAGRED0, Rafael, y PUIG-SAMPER, Miguel Ángel, (Editores), (2007) Imágenes de la Comisión Científica del Pacífico en Chile, Editorial Universitaria, Santiago.

SARLO, Beatriz, (1997) Instantáneas, Medios, ciudad y costumbres en el fin de siglo, 1996, Espasa Calpe Argentina/ Ariel, Buenos Aires, $2^{\text {a }}$ ed.

SILVA, Armando, (1992) Imaginarios Urbanos, Tercer Mundo Editores,

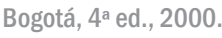

(2004) Imaginarios Urbanos: hacia el desarrollo de un urbanismo desde los ciudadanos, Metodología, Convenio Andrés Bello, Bogotá. SUBERCASEAUX, Benjamín, (1940) Chile o una loca geografía, Editorial Universitaria, Santiago, 2001. 